\title{
Ewing Sarcoma of Bone
}

National Cancer Institute

\section{Source}

National Cancer Institute. Ewing Sarcoma of Bone. NCI Thesaurus. Code C4835.

A small round cell bone tumor that lacks morphologic, immunohistochemical, and electron microscopic evidence of neuroectodermal differentiation. It represents one of the two ends of the spectrum called Ewing sarcoma/peripheral neuroectodermal tumor. It often affects the diaphysis or metaphyseal-diaphyseal portion of long bones. Clinical findings include pain and a mass in the involved area. Fever, anemia, leukocytosis, and an increased sedimentation rate are often seen. X-ray examination reveals osteolytic lesions. The prognosis depends on the stage, anatomic location, and size of the tumor. 